Cad.Est.Ling., Campinas, (41):177-189, Jul./Dez. 2001

\title{
PROCESSOS DE REFERENCIAÇÃO EM DUAS CONFIGURAÇÕES NARRATIVAS: O CONTO POPULAR E A ESTÓRIA ORAL ${ }^{1}$
}

\author{
ANNA CHRISTINA BENTES \\ UNICAMP
}

\begin{abstract}
This article describes how narrators from Brazilian Amazon region configurate oral tradition in two different ways. The first way, called "folk-tale" is characterized considering the fact that narrators, when telling their stories, privilege the dimensions of repetition and stability. The second one, called "oral story", is characterized considering the fact that narrators, when telling their stories, privilege the dimensions of difference and instability. The present analysis of both configurations takes into account two aspects (i) the enunciative situation in which they were produced and (ii) the textual and discursive strategies developed by narrators. Folk-tales present (i) fixed plots, which are common-shared and (ii) referenciation strategies that do not show the discursive instances in which the stories are produced. Oral stories reconstruct tradition radically. In this way, they do not present fixed plots, what makes possible the emergency of versions that are distant from the formulaic nature of oral tradition. Referenciation strategies present in this second narrative configuration are much more varied and they also make possible the emergency of the discursive instances in which narratives are produced.
\end{abstract}

\section{REFLEXÕES INICIAIS SOBRE AS NOÇÕES DE CONTO POPULAR E ESTÓRIA ORAL}

No conjunto de narrativas ${ }^{2}$ da Amazônia paraense que analiso neste artigo, parece que a grande maioria dos narradores construiu suas estórias recorrendo a determinados recursos temáticos, enunciativos e textuais que as inscreveram em determinados domínios do discurso, que não necessariamente foram demandados a priori, mas que se

\footnotetext{
${ }^{1}$ Este artigo apresenta uma parte de um dos capítulos de minha tese de Doutorado intitulada "A arte de narrar: da constituição das estórias e dos saberes dos narradores da Amazônia paraense", defendida em novembro de 2000, no Instituto de Estudos da Linguagem da Universidade Estadual de Campinas.

${ }^{2} \mathrm{O}$ corpus da tese foi constituído de 30 narrativas, retiradas de um conjunto de obras publicadas no ano de 1995, em três volumes, denominados Belém conta...., Abaetetuba conta...., Santarém conta...., numa iniciativa da Universidade Federal do Pará e da editora CEJUP. Estas publicações resultaram de um longo trabalho de pesquisa desenvolvido, desde 1993, pelo programa "O Imaginário nas Formas Narrativas Orais Populares da Amazônia Paraense (IFNOPAP), coordenado pelos professores Maria do Socorro Simões e Christophe Golder.
} 
constituíram como aquele(s) que foram predominantemente enunciados (e não outros). Neste trabalho, pretendo apresentar como as diferentes estratégias de referenciação utilizadas pelos narradores podem nos revelar dois modos de inscrição no mundo narrado, a saber, o conto popular e a estória oral.

De maneira geral, os contadores de estórias instituíram, junto com seu(s) ouvinte (s) / interlocutor (es), o famoso acordo ficcional, chamado por Coleridge de "suspensão da crença": o ouvinte/leitor sabe que o que está sendo narrado é uma estória imaginária, mas nem por isso deve pensar que o narrador está contando mentiras ${ }^{3}$. Esta é, a meu ver, a "cena enunciativa" que se encontra na base da construção destas narrativas, na qual um sujeito, ao enunciar o que enuncia, pressupõe uma espécie de "ritual social da linguagem, implícito, partilhado pelos interlocutores" (Maingueneau,1989:30). Ainda para Maingueneau, numa perspectiva pragmática, "ao enunciar, eu me concedo um certo lugar e atribuo um lugar complementar ao outro, peço-lhe que se mantenha nele e que reconheça que sou exatamente aquele que fala do meu lugar" (op. cit.:32). É neste sentido que estarei atribuindo às narrativas da Amazônia paraense o estatuto de textos ficcionais ${ }^{4}$.

Uma outra característica do "mundo narrado" é o fato de a situação enunciativa ser de caráter distenso, o que faz com que a atitude dos interlocutores em relação ao dito seja a de descomprometimento, já que eles (os interlocutores) não estão implicados.

Dado que o estabelecimento do acordo ficcional na situação enunciativa mencionada acima é a base da produção das narrativas, postulo que as narrativas produzidas inscrevem-se no domínio do ficcional, domínio este que institui também um determinado tipo de interação entre os interlocutores, a saber, aquela em que há uma atenção dividida. Esta atenção é dividida porque o público encontra-se envolvido tanto com o que está sendo narrado como com o ato de narrar. E o narrador, ao mesmo tempo em que encontra-se envolvido com seu público, também possui uma vocação para a construção prioritária de um jogo de relações internas ao texto. Esta vocação para o jogo de construções internas ao texto está ligada à estabilização, conforme ressalta Maingueneau (1995), dos enunciados orais submetidos às restrições da instituição literária. Sendo assim, postulo que as narrativas orais da Amazônia paraense encontramse submetidas às restrições da instituição literária em função de fatores como (i) a

\footnotetext{
${ }^{3}$ Esta formulação está baseada no que Umberto Eco diz sobre o acordo ficcional. Fiz uma adaptação, já que Eco nos fala de textos escritos e este trabalho diz respeito a textos orais publicados. O trecho original é o que se segue: "a norma básica para se lidar com uma obra de ficção é a seguinte: o leitor precisa aceitar tacitamente um acordo ficcional, que Coleridge chamou de "suspensão da crença". O leitor tem de saber que o que está sendo narrado é uma história imaginária, mas nem por isso deve pensar que o escritor está contando mentiras. De acordo com John Searle, o autor simplesmente finge dizer a verdade. Aceitamos o acordo ficcional e fingimos que o que é narrado de fato aconteceu. (Umberto Eco, Seis passeios pelo bosque da ficção, p 81).

${ }^{4}$ Ao postular um estatuto ficcional para as narrativas, espero poder deixar claro que não assumo uma divisão rígida e estanque entre o ficctício e o real. Ao contrário, assumo neste trabalho as postulações de Iser [1991] (1996b), para quem enxergar a ficcionalidade não significa retirar dela os atributos que definem a realidade, mas significa assumir que o texto ficcional contém elementos do real sem que se esgote na descrição deste real. Uma das características do chamado discurso ficcional é exatamente a capacidade de operar uma articulação de diferentes campos de referência que resulte em uma "transgressão dos limites", de forma a fazer valer o imaginário de forma a possibilitar o alcance de uma realidade de outro modo inacessível.
} 
filiação das narrativas à tradição oral e (ii) as funções desempenhadas por elas na comunidade que lhes dá origem. Há ainda um terceiro fator que determina a inscrição destas narrativas no domínio do ficcional: o fato de elas constituírem-se em determinados gêneros do discurso, que, por sua vez, encontram-se em relação com outros gêneros da instituição literária.

As duas configurações narrativas, o conto popular e a estória oral, foram postuladas considerando-se, por um lado, (i) o saber que o ouvinte/leitor possui sobre os conflitos engendrados na trama e/ou também sobre a forma de resolução destes conflitos e (ii) o conjunto de estratégias textuais e enunciativo-discursivas operadas pelo narrador, estratégias estas que evidenciam um saber de natureza lingüístico-discursiva (cf. Koch, 1997, Marcuschi, 2000) e um saber pragmático, relacionado aos rituais de narrar instaurados. Esta classificação provisória dos gêneros orais produzidos na situação enunciativa anteriormente descrita não tem por objetivo postular nenhuma tipologia, já que concebo os gêneros como tipos relativamente estáveis de enunciados (Bakhtin, 1979) e, também, de acordo com propostas teóricas mais recentes, como "qualquer forma textual caracterizada por propriedades indutivamente obtidas que não se aplicam a todos os textos" (Gülich, 1986 apud Marcuschi, 2000:80). Sendo assim, a classificação das narrativas proposta neste trabalho constitui-se em uma classificação aberta, pois, segundo Marcuschi (2000:83), "os gêneros textuais não apresentam uma homogeneidade formal".

No entanto, é impossível perder de vista que a busca da ordem (mesmo de uma ordem de caráter empírico e provisório, como esta a ser descrita ao longo deste artigo) somente é possível, no dizer de Ricoeur (1995:33), se considerarmos que esta ordem se deve (i) ao fato de as culturas produzirem obras que se deixam aparentar entre si, (ii) ao fato de esta ordem poder ser atribuída à imaginação produtora, da qual ela constitui o esquematismo e (iii) ao fato de esta ordem possuir uma dimensão temporal, a da tradicionalidade 5 . Para Ricoeur, as diversas configurações narrativas remetem ao esquematismo da inteligência narrativa, "forjada pela freqüentação das narrativas transmitidas por nossa cultura". Para o autor, é exatamente esta "inteligência narrativa" que devemos tentar compreender, ao invés de procurarmos a racionalidade a-histórica da semiótica narrativa. Desse modo, a tentativa de descrição dos modos de configuração narrativa pressupõe, necessariamente, a compreensão de que o saber que rege a "inteligência narrativa" da qual se pode depreender uma determinada configuração possui uma dimensão trans-histórica, ou seja, que é resultado de um processo cumulativo constante, que pressupõe tanto a sedimentação de ordens como a ruptura destas mesmas ordens.

Se, por um lado, considero que as narrativas da Amazônia paraense que compõe este corpus podem ser agrupadas como submetidas a dois diferentes "conjuntos de

\footnotetext{
${ }^{5}$ Para Ricoeur (1985:26), "a tradicionalidade é esse fenômeno, irredutível a qualquer outro, que permite que a crítica se mantenha a meio caminho da contingência de uma simples história dos "gêneros", dos "tipos" ou das obras singulares que dependem da função narrativa e de uma eventual lógica das possibilidades narrativas que escaparia a qualquer história. A ordem que é possível destacar dessa auto-estruturação não é nem histórica, nem a-histórica, mas trans-histórica, no sentido de que atravessa a história de um modo cumulativo mais do que simplesmente aditivo. Mesmo se comporta rupturas, mudanças súbitas de paradigmas, esses próprios cortes não são simplesmente esquecidos: tampouco fazem esquecer o que os precede e aquilo de que eles nos separam: também fazem parte do fenômeno de tradição e de seu estilo cumulativo".
} 
coerções comuns" (Maingueneau, 1989), ou seja, como constituindo dois gêneros do discurso, o conto popular e a estória oral, é porque compreendo que os gêneros, além de se constituírem em formas relativamente estáveis de enunciados, também presumem um contrato específico pelo ritual que definem.

E se, ao mesmo tempo, compreendo o conjunto de estórias analisadas como configurações narrativas, é porque estou tentando considerar também os movimentos textuais e discursivos através dos quais o narrador pode colocar uma determinada ordem em movimento, pode fazer de uma seqüência de acontecimentos uma forma específica de apreensão simbólica do mundo. Acredito que o conceito de gênero do discurso e o conceito de configuração narrativa podem ser aproximados na medida em que apontam para dois planos de análise: por um lado, na definição de um gênero do discurso, privilegia-se o ritual social no qual os diversos gêneros são produzidos; por outro lado, no conceito de configuração narrativa, pressupõem-se os movimentos do narrador que colocam uma determinada ordem em movimento, em outras palavras, um "trabalho do sujeito sobre o seu dizer" (Geraldi, 1991, Koch, 1997).

Sendo assim, vejamos como estas duas configurações, o conto popular e a narrativa oral, podem ser, inicialmente diferenciadas. O primeiro critério estabelecido acima foi aquele que diz respeito ao saber do público sobre os conflitos engendrados na trama e também sobre a forma de resolução destes conflitos. O fato de haver um conhecimento prévio e genérico, por parte do público, da seqüência de eventos que compõem uma determinada estória pode definir uma determinada narrativa como conto popular.

Acredito que este critério pode ser considerado operacional porque as narrativas se inscrevem na chamada "corrente da tradição oral", o que faz com que o ritual de linguagem pressuposto seja aquele em que se espera do narrador que ele narre justamente o que já é conhecido, o que faz parte da dimensão temporal da tradicionalidade, o que necessariamente remete a uma memória coletiva. Esta exigência da identidade e da repetição parece ser um dos fatores que constrói a autoridade do narrador, que sempre é encarado por seu público, como um homem sábio, como aquele possuidor de uma linguagem capaz de "trazer de volta o que desapareceu" (Benveniste, 1988:27), como uma espécie de depositário dos conteúdos importantes para uma determinada comunidade. Se o narrador possui a tarefa de guardar os "tesouros" da comunidade, a comunidade possui a tarefa de estar sempre em busca destes "tesouros", que, como afirma Warner (1999), nos fazem acreditar "que o mundo pode ser recriado segundo a imagem do desejo". Assim, este reconhecimento por parte do público de um material que é de todos, de um "estoque comum", é, a meu ver, o que caracteriza o conto popular. Se o conto popular caracteriza-se pela reiteração de uma certa identidade temática e estrutural, isto ocorre como resultado de uma complexa rede de interações entre o narrador e outros narradores, entre o narrador e seu público imediato, entre o narrador e o seu próprio dizer, entre o público e a narrativa. Uma grande parte dos contos selecionados para publicação trazem como temas figuras lendárias da região: o boto, a matinta-perera, a cobra grande, o curupira, a mãe d'água, etc. No entanto, há outros tipos de contos que estão presentes nas publicações: aqueles de caráter não-regional, mas que fazem parte de uma rede complexa de circulação de determinadas narrativas, que não 
apresentam maiores modificações, tanto do ponto de vista temático, como do ponto de vista estrutural, que aparecem em culturas muito díspares.

Já a estória oral caracteriza-se por reelaborar um (ou mais de um) elemento da tradição, sem que seja possível um reconhecimento por parte do público das formas que os conflitos vão tomar e das formas como vão ser resolvidos. Em outras palavras, a estória oral caracteriza-se não pela presença de um enredo fixo, "publicamente partilhado", como nos contos populares, mas por uma reelaboração mais radical dos elementos da tradição oral. Na verdade, as estórias orais enfatizam com maior força o "intuito discursivo" do narrador, ou seja, as estórias orais são configurações onde se pode reconhecer com mais facilidade o discurso do narrador. As estórias orais também apresentam um caráter regional e um outro não-regional. Este último tipo de estória não tematiza um personagem do folclore da região, mas apresenta temas recorrentes, tais como as estórias sobre as metamorfoses de homens e mulheres em animais ou seres "encantados", sobre aparições e/ou fantasmas. Apesar de os motes serem mais ou menos conhecidos, a forma de "tecer a intriga" é bastante imprevisível, o que nos faz afirmar que neste tipo de configuração ocorre uma reelaboração radical de elementos ou temas da tradição.

Tendo apresentado brevemente algumas diferenças entre o conto popular e a estória oral, passo agora a descrever uma estratégia textual, a saber, a referenciação, que se constitui em um indício de como os narradores não se inscrevem da mesma maneira na chamada "corrente da tradição oral".

\section{ALGUNS PROCESSOS DE REFERENCIAÇÃO NAS NARRATIVAS ORAIS POPULARES DA AMAZÔNIA PARAENSE}

A referenciação é concebida, neste trabalho, como "um processo realizado negociadamente no discurso e que resulta na construção de referentes", ou seja, é uma "atividade discursiva, de tal modo que os referentes passam a ser objetos-de-discurso e não realidades independentes" (Koch e Marcuschi, 1998:173). Segundo os autores, os processos de referenciação possibilitam a construção de objetos-de-discurso que não préexistem ao discurso enquanto tal, mas que são construídos no interior do próprio discurso. Koch (1999), baseada em Mondada e Dubois (1995), assume a postulação de que há uma instabilidade das relações entre as palavras e as coisas. Isto significa dizer, ainda segundo Koch, que, no discurso, os processos de categorização dependem muito mais da multiplicidade de pontos de vista que os sujeitos exercem sobre o mundo do que de restrições impostas pela materialidade deste. Sendo assim, no discurso, "quer se trate de objetos sociais, quer de objetos "naturais", aquilo que é habitualmente considerado como um ponto estável de referência para as categorias, pode ser de-categorizado, tornado instável, evoluir sob o efeito de uma mudança de contexto ou de ponto de vista". (Koch, 1999:06). Para a autora, isto não significa negar a existência da realidade extramente, nem tampouco estabelecer a subjetividade como parâmetro do real, mas apenas afirmar que "nossa maneira de ver e dizer o real não coincide com o real" (op. cit.:08). Em outras palavras, a autora afirma que o que acontece é uma reelaboração/reconstrução 
do real, reelaboração esta que "deve obedecer a restrições impostas pelas condições culturais, sociais, históricas e, finalmente, pelas condições de processamento decorrentes do uso da língua" (op.cit.:08).

Se, conforme se deduz do que foi dito anteriormente, "o discurso constrói aquilo a que faz remissão", faz-se também necessário reconhecer que

o discurso opera com uma memória compartilhada, 'publicamente' alimentada pelo próprio discurso" (Apothéloz, Reichler-Béguelin), sendo os sucessivos estágios dessa representação responsáveis, ao menos em parte, pelas seleções feitas pelos interlocutores, particularmente em se tratando de expressões referenciais (Koch, 1999:08).

É neste sentido que postulo que as estratégias de referenciação por meio das quais os narradores procedem à categorização ou recategorização discursiva dos referentes são diferentes nas duas configurações narrativas, a saber, o conto popular e a estória oral. Koch afirma que a noção de "memória publicamente partilhada" pode ter várias formulações em diferentes perspectivas teóricas, sendo uma delas a de "memória discursiva" (Berrendonner, Reichler-Béguelin, 1989 apud Koch, 1999). A meu ver, é exatamente esta "memória discursiva" a responsável pelo recurso a um certo conjunto de estratégias de referenciação nos contos populares e a um outro conjunto de estratégias de referenciação nas estórias orais. No conjunto de contos populares que compõe o corpus desta tese, o narrador predominantemente utiliza no início de sua narrativa expressões nominais indefinidas. Há também dois casos de uso de expressão nominal definida $(1,4)$ e um caso de uso de pronominalização (11). Vejamos os exemplos.

\begin{tabular}{|c|c|c|}
\hline Título & Volume & Estratégias de Referenciação \\
\hline 1. Os pescadores e o boto & Santarém conta & "Tinha dois pescadores..." \\
\hline 2. Besta boto & Santarém conta & "Era uma rapariga...." \\
\hline 3. A inveja & Santarém conta & "Um rapaz que ficou..." \\
\hline 4. Boto chupador & Santarém conta & "O velho tinha uma filha..." \\
\hline 5. O rico e o pobre & Abaetetuba conta & $\begin{array}{l}\text { "Eu vou contar de um rico e um } \\
\text { pobre }\end{array}$ \\
\hline 6. O encanto de Honorato & Abaetetuba conta & “(...) uma senhora ficou ...” \\
\hline 7. A ilha da cobra & Abaetetuba conta & "Era uma vez uma bela ilha" \\
\hline 8. Encanto dobrado & Abaetetuba conta & "(...) uma senhora ...”" \\
\hline 9. A princesa dos doze vestidos & Belém conta & $\begin{array}{l}\text { "Era uma vez um rei que tinha } \\
\text { uma filha }\end{array}$ \\
\hline 10. Boto bonito & Belém conta & "(...) que houve uma festa...” \\
\hline 11. Como virar corcunda & Belém conta & $\begin{array}{l}\text { "Ele era... ele vivia numa cidade, } \\
\text { sabe...." }\end{array}$ \\
\hline 12. A cobra de prainha & Belém conta & "Existia em Prainha um homem \\
\hline
\end{tabular}

Nas estórias orais, como veremos na sessão seguinte, as estratégias de referenciação no início de cada narrativa podem ser diferentes das acima descritas. Em sua obra sobre os Dogon (povo africano que habita a Nigéria), Calame-Griaule (1965) afirma, que, nos contes de personnes deste povo, ao contrário do que acontece nas fábulas, os 
personagens humanos são os indivíduos e não os protótipos da espécie. No entanto, eles raramente são designados pelo nome e, em geral, são designados por expressões nominais indefinidas, como nos contos aqui analisados. A autora afirma que, malgrado a aparente individualidade, os personagens assim designados são construídos como símbolos, sendo que nomeá-los lhes conferiria uma realidade humana que eles não possuem. Acredito que a presença maciça de expressões nominais indefinidas no início dos contos populares aqui analisados evidencia também um propósito de construir estórias que não possibilitem uma individualização dos referentes.

A utilização de expressões nominais definidas $(1,4)$, em outros contextos, constituise em uma operação de seleção, dentre as propriedades atribuíveis a um referente, daquela que, em dada situação discursiva é relevante ao seu projeto de dizer (cf. Koch, 1999:13-14). O uso de artigo definido em um grupo nominal pode também remeter não só a informações do contexto precedente, como também a elementos da situação comunicativa (cf. Koch, 1989:34-35). No entanto, a utilização destas expressões nos contos populares se, por um lado, revela a seleção de uma das propriedades passíveis de serem atribuídas ao referente, por outro lado, deixa de indicar uma remissão ao contexto precedente. Assim, parece que o uso das expressões nominais definidas nos contos populares funciona como uma tentativa, por parte do narrador, de obedecer à restrição imposta pelo gênero, a saber, a não individualização dos referentes de que se fala.

De qualquer maneira, o uso de expressões nominais definidas e o uso de pronomes no início de contos populares evidencia a tradicionalidade, tal como ela é concebida por Ricoeur (1995): um fenômeno que não pode ser compreendido como apontando para uma fixidez de formas e conteúdos, mas, ao contrário, como um fenômeno em que a identidade e a ruptura encontram-se inextrincavelmente mescladas. Assim, as outras estratégias de referenciação que não a do uso de expressões nominais indefinidas no início dos contos populares constituem uma ruptura, no nível textual, de um "esquematismo" historicamente construído no/pelo conto popular. Além disso, estas rupturas também mostram a qualidade da relação que os diferentes narradores estabelecem com a memória discursiva: enquanto alguns reproduzem as estratégias de referenciação tradicionais de uma dada configuração narrativa, outros produzem rupturas nas formas de dizer tradicionalmente concebidas, sem que isto descaraterize o seu projeto de dizer. No entanto, até aqui, não foi possível perceber uma variação muito grande nas estratégias de referenciação para dar início aos contos populares: dos 11 contos populares que fazem parte do corpus, apenas um foi iniciado com um pronome ("ele") e dois outros, com expressões nominais definidas ("dois pescadores", "o velho"). Acredito que isto também evidencia uma performance dos narradores bastante próxima daquilo que é esperado, pelo menos em relação à forma de iniciar os contos.

Em termos de progressão referencial, os contos populares regionais apresentam fenômenos interessantes. No caso dos contos que têm como tema a figura do boto (que se transforma em homem e se transforma em boto novamente), a progressão referencial é construída de maneira a preservar esta ambigüidade de um dos referentes textuais. Por exemplo, no conto Os pescadores e o boto, do volume Santarém conta..., na primeira vez em que o animal é mencionado, o narrador utiliza uma expressão nominal definida (“o boto"), o que, neste caso, parece indicar que não se vai tematizar neste conto um boto 
qualquer, mas a figura mítica do boto. Este mesmo referente textual somente é retomado pela mesma expressão nominal definida (“o boto"), quando o narrador já se encontra no fundo do rio. Depois, até o final do conto, este mesmo referente é designado por outra expressão nominal definida ("esse boto") e pelo pronome "ele". O procedimento de resguardar a ambigüidade da identidade não se refere, no caso deste conto, ao boto que foi ferido: ele foi ferido na condição de animal e foi nesta condição que foi tratado pelo pescador no fundo do rio. Não há ambigüidade na estratégia de referenciação, que é, neste caso, pouco inovadora.

A ambigüidade referencial é construída quando se trata de ativar um novo referente no texto: os soldados (que o narrador deixa implicado que eram botos) que foram buscar o pescador para levá-lo com eles para o fundo do rio. A partir deste momento, o narrador encena dois diálogos com um dos soldados/botos, mas, em momento algum, enuncia diretamente "o soldado me disse" ou ainda "o boto me falou". As estratégias de referenciação utilizadas para deixar este referente opaco quanto à sua identidade são: a elipse do sujeito e a pronominalização. Vejamos um trecho da narrativa com os exemplos:

(1) Aí, então, ele (o pescador) estava muito longe, e aí veio aquela canoa cheia de soldado. Aí, foi encostando na canoa. Aí, encostou junto dele e disse:

- Mas por quê? O que eu fiz?

- $\quad$ Não sei o quê, mas você está preso, e vamos logo.

Aí, ele embarcou na canoa e saiu, quando chegou no meio do rio, aí, ele disse:

Agora, feche os olhos.

Aí, ele fechou o olho, e quando mandaram ele abrir ... quando ele abriu, diz que tinha um palácio. Aí, mas tudo era boto. Só era boto, e chegou lá no quarto, estava o boto lá deitado. Estava doente e com ferimento, e disse:

- Você está vendo esse boto, aí? É aquele que, aquele dia, que você andava pescando, você furou. Acertou ele. Ele está doente. Você vai tratar dele, se ele ficar bom, você volta, se ele não fica, você vai ficar aqui (Hermita Oliveira de Noronha, Santarém conta, p. 32-33).

O predomínio de estratégias de referenciação, tais como as acima exemplificadas, nos contos sobre o boto, parece estar também relacionado ao fato de estes contos remeterem a práticas culturais longínquas que submetiam seus membros a um determinado conjunto de proibições, baseado em uma lógica peculiar: aquela da naturalização de um poder mágico, inerente a certas coisas, animais ou pessoas. Sendo assim, a figura do boto vem sendo, ao longo dos tempos, discursivamente construída de forma a manter esta aura de mistério e de perigo que a envolve.

Ao contrário do que acontece nos contos populares, onde ocorre um predomínio das expressões nominais indefinidas, na estória oral não se pode dizer que haja o predomínio absoluto de uma determinada estratégia de referenciação. Vejamos o quadro abaixo: 


\begin{tabular}{|c|c|c|}
\hline Tìtulo & Obra & Estratégias de referenciação \\
\hline 1. O boto e o rapaz & Santarém conta & Ele ia lá pro barco, né? \\
\hline 2. O bicho & Santarém conta & $\begin{array}{lll}\text { Dona Maricota } & \text { e Seu Jovino } \\
\text { moravam... } & & \\
\end{array}$ \\
\hline 3. A morta viva & Santarém conta & Eles moravam longe... \\
\hline $\begin{array}{l}\text { 4. Parece mentira, mas não } \\
\text { é }\end{array}$ & Santarém conta & $\begin{array}{l}\text { Era uma noite, quando eu saí para } \\
\text { pescar... }\end{array}$ \\
\hline 5. Fut & Santarém conta & $\begin{array}{l}\text { Carnaval! Aí, minha filha, Quando } \\
\text { foi sábado, ele disse.. }\end{array}$ \\
\hline 6. A porca noturna & Santarém conta & A mulher virava porca. \\
\hline \begin{tabular}{lccc|} 
7. & Essas coisas que \\
aparecem
\end{tabular} & Abaetetuba conta & $\begin{array}{l}\text { Outra vez, eu fui lanternar com um } \\
\text { colega, sabe? }\end{array}$ \\
\hline 8. Uma visita & Abaetetuba conta & $\begin{array}{l}\text { Esse meu pai de criação e cunhado, } \\
\text { finado Raimundo, ele contava } \\
\text { muito, muita, muitos casos de } \\
\text { visagem... }\end{array}$ \\
\hline 9. Tormento & Abaetetuba conta & $\begin{array}{l}\text { Era uma vez um rapaz que se } \\
\text { chamava Doca. }\end{array}$ \\
\hline 10. Só eu vendo & Abaetetuba conta & $\begin{array}{l}\text { A minha tia foi chamada, numa } \\
\text { certa ocasião, para cuidar de um } \\
\text { homem... }\end{array}$ \\
\hline 11. Sherlock de Barcarena & Abaetetuba conta & $\begin{array}{l}\text { Depois de um dia cheio de } \\
\text { trabalho, *voltava para casa... }\end{array}$ \\
\hline 12. Defunto pesa & Abaetetuba conta & O irmão mais velho foi e disse..... \\
\hline 13. O ogre & Belém conta & $\begin{array}{l}\text { Era um rapaz que ele... Era uma } \\
\text { moça... }\end{array}$ \\
\hline 14. Um luxo de matinta & Belém conta & $\begin{array}{l}\text { Era duas moças amiga, amiga, } \\
\text { amiga. }\end{array}$ \\
\hline 15. Vira, vira porco & Belém conta & Tem uma ilha que chamam.. \\
\hline 16. A coragem de Teresa & Belém conta & $\begin{array}{l}\text { A Teresa... Nós morávamos muito } \\
\text { tempo lá .... }\end{array}$ \\
\hline 17. O bloco & Belém conta & $\begin{array}{l}\text { Numa tarde de Carnaval, né? Era } \\
\text { até Domingo gordo. Nós saímos e } \\
\text { fomos para a praça ... }\end{array}$ \\
\hline 18. Quem é essa mulher & Belém conta & $\begin{array}{l}\text { Era uma vez... Aconteceu verídico, } \\
\text { certo? Ah! Ah! Ah! *Trabalhava } \\
\text { na linha do Souza. Eu, Elson } \\
\text { Cardoso Neves, motorista do } \\
\text { ônibus, do carro } 20 .\end{array}$ \\
\hline
\end{tabular}

Ao trilhar o caminho das estórias orais quando adentra o bosque da narrativa, o narrador revela um comprometimento muito menor com as "fórmulas" que caracterizam a tradição. É somente considerando este "descompromisso" que se pode compreender a 
variedade de modos que os inícios das estórias orais apresentam: o recurso à pronominalização (7), às expressões nominais definidas (5), às expressões nominais indefinidas (3), a nomes próprios (1) e à elipse (2). Além disso, como foi afirmado anteriormente, se as estórias orais caracterizam-se por mostrar mais explicitamente o "intuito discursivo" do narrador, então, não há mais razão para construir o apagamento da instância discursiva na qual aquela determinada estória é produzida. Acredito que isto propicia mais freqüentemente os inícios em primeira pessoa (marcada ou não-marcada) e os inícios com expressões nominais definidas que apresentam pronomes possessivos relacionando o referente textual ao narrador ("Esse meu pai de criação", "A minha tia"). A meu ver, a presença dos pronomes de $3^{\text {a }}$ pessoa ("Ele", "Eles") no começo de algumas estórias somente pode ser explicada se analisarmos também a forma como ocorre a progressão referencial nestas estórias.

Na estória $O$ boto e o rapaz, do volume Santarém conta..., o narrador nos fala que "ele" (primeiro personagem) ia dormir lá no barco, a mando do pai e que quando "ele" já estava deitado, "ele" via que "ela" chegava. Até o final da estória, a primeira personagem, designada por "ele", não é definida de forma alguma. O narrador repete o pronome até o final da seqüência de eventos que envolve esta personagem. A segunda personagem é designada por "ela", "aquela moça" e, depois, até o final da sequiência de eventos, é designada por "ela". É no diálogo que o narrador trava com o primeiro personagem, depois de terminado o relato, que passamos a ter uma informação nova sobre "ele": chama-se Davi e é conhecido do narrador. Sobre "ela", somente ficamos sabendo sua identidade a partir da fala final do narrador: "Coitado, era o boto que dormia com ele". Assim, ficamos sabendo que "ela" era "ele". Sobre esta narrativa, cabe uma afirmativa de Umberto Eco: "às vezes, o narrador quer nos deixar livres para imaginarmos a continuação da estória". Neste caso, a fala final do narrador, finalmente identificando o objeto-de-discurso do qual vinha falando, justifica o porquê de narrar sobre um rapaz que, todas as noites, deita com uma moça: a moça não era bem uma moça, era o boto. Este comentário final sobre o relato inicial, que, aparentemente, não apresenta a chamada "complicação", leva-nos a reconstruir toda a estória, deixando-nos livres para imaginarmos os sentidos possíveis para este acontecimento.

Na estória A morta viva, também do volume Santarém conta..., as duas personagens principais são designadas como "eles" no início da estória. No decorrer da narrativa, a personagem feminina é retomada pelas expressões nominais definidas "a mulher dele", "a mulher", "minha mulher", "aquela mulher morta", "aquela pessoa", "sua mulher" e pelo pronome "ela". A personagem masculina é retomada pela expressão nominal definida "o marido" e pelo pronome "ele".

Na estória Fut, do volume Santarém conta..., a personagem masculina designada por "ele" no início do conto é retomada pelas expressões nominais definidas "o homem", "aquela pessoa", "aquele bicho", "o bicho Fut", "o marido dela" e pelo pronome "ele". A personagem feminina, designada também pela primeira vez por "ela", é retomada pelas expressões nominais definidas "a mulher" e "essa mulher" e pelo pronome "ela".

Estas duas últimas estórias apresentam recursos comuns: duas personagens (um homem e uma mulher), sendo que uma delas sofre uma metamorfose e, a outra, assiste a este acontecimento. Sobre a personagem que se transforma, a progressão referencial 
evidencia o processo de transformação. Sobre a personagem que assiste a tudo, ficamos sabendo apenas o suficiente: que é casada com a que se transforma.

Sempre há um trabalho sobre o dizer. Mas o caso do uso de pronomes no início das estórias assinala mais fortemente este trabalho de construção do objeto-de-discurso. Não há como fugir deste chamado: somente saberemos quem é "ele" ou quem são "eles", se continuamos a seguir as pistas que o narrador vai, aos poucos, fornecendo. No entanto, ao final das três estórias, continuamos a saber muito pouco sobre as personagens e sobre a natureza dos acontecimentos narrados. Afinal, limites foram transgredidos, ordens foram alteradas, instabilidades foram mostradas.

A meu ver, estas encenações nos colocam frente a frente com "algo diferente da própria vida empírica" (Iser, 1996). Estas estórias revelam a "plasticidade da natureza humana", de que fala Iser (1996). Se a estória sobre o Fut é uma estória que nos permite encenar a liberação das limitações sociais, a estória sobre A morta viva nos permite encenar uma liberação das nossas restrições biológicas. Dessa forma, estamos, segundo Iser (1996b), constantemente tematizando nossa alteridade e construindo formas de acesso às inúmeras possibilidades que se constituem na resposta ao inacessível (ao problema da morte, por exemplo) ou àquilo que nos é culturalmente interditado (ao problema da satisfação dos prazeres, por exemplo). Neste artigo, estive interessada em discutir como as estratégias de referenciação evidenciam uma determinada configuração narrativa, a saber, a estória oral, que se caracteriza por ser uma reelaboração da tradição. $\mathrm{Na}$ análise do modo de progressão referencial na estória $O$ boto e o rapaz, foi possível perceber que esta estória progride de forma a construir, fundamentalmente, através das estratégias de referenciação, uma aura de mistério em torno do acontecimento.

\section{CONSIDERAÇÕES FINAIS}

Diante do exposto acima, é possível afirmar que os contos populares caracterizamse, então, por apresentarem um enredo fixo, publicamente partilhado, por apresentarem estratégias de referenciação que apagam as instâncias discursivas nas quais as narrativas são produzidas. As estórias orais, por outro lado, caracterizam-se por constituírem-se em reelaborações da tradição e, por isso mesmo, não apresentam um enredo fixo. As estratégias de referenciação presentes nestas configurações narrativas são variadas e não há a necessidade de se construir um apagamento das instâncias discursivas nas quais as narrativas são produzidas.

Espero ter deixado claro, ao longo deste artigo, que as duas configurações narrativas acima descritas são modos de inserção do sujeito no mundo narrado e que o fato de cada modo apresentar um conjunto de características que o diferencia do outro não significa dizer que estas características são exclusivas de cada um dos modos. Ao contrário, espero ter conseguido ser coerente, na proposição destes modos de configuração, com o pressuposto teórico que está na base deste trabalho: o de que trabalhar com a tradição significa compreendê-la como um fenômeno que comporta, ao mesmo tempo e de forma inseparável, as dimensões da identidade e da ruptura, da repetição e da inovação. 
O modo de os narradores inscreverem-se no mundo narrado é marcado textualmente. Nos contos populares, por exemplo, a progressão textual é determinada pela presença de um enredo fixo, caracterizado pela necessária dupla "conflito/resolução". Já nas estórias orais, a categoria "resolução" não é obrigatória, o que confere um caráter de inacabamento à narrativa.

No início dos contos populares, as estratégias de referenciação não são inovadoras, ocorrendo um predomínio da utilização de expressões nominais indefinidas, o que não possibilita uma individualização dos referentes. Esta não individualização do referente é uma restrição imposta pelo gênero, restrição esta que a maioria dos narradores tenta seguir à risca. No entanto, há um número menor de estratégias de referenciação que não obedece estritamente a esta restrição, o que revela uma ruptura, no nível textual, de um "esquematismo" historicamente construído no/pelo conto popular. O predomínio de uma estratégia de referenciação em detrimento de outras revela a maneira como os narradores relacionam-se com a memória discursiva, tentando reproduzir ao máximo as estratégias de referenciação que caracterizam a "fórmula" de iniciar o gênero conto popular.

No início das estórias orais, no entanto, em consonância com a possibilidade instaurada pelo próprio gênero de uma reelaboração mais livre daquilo que é julgado como tradição oral, ocorre uma variedade de estratégias de referenciação, sendo que cada forma de iniciar encontra-se bem adaptada ao projeto de dizer do narrador.

Esta breve análise mostra que os contos populares e as estórias orais não devem ser consideradas como "narrativas simples". Ao contrário, as diferentes estratégias de referenciação utilizadas pelos narradores apontam para o fato de que pode haver uma sofisticação do "tecer da intriga" em narrativas orais populares e não apenas em narrativas escritas.

\section{REFER̂̂NCIAS}

BAKHTIN, M. (1992). Estética da criação verbal. São Paulo: Martins Fontes. (Edição Original, 1979).

BENVENISTE, E. (1988). Problemas de lingüística geral I. Campinas, SP: Pontes: Editora da UNICAMP. (Edição original: 1966)

CALAME - GRIAULE, G. (1965). Etnologie et Langage. La parole chez les Dogon. Paris: Institute d`Etnologie.

CERTEAU, M. de. (1996). A invenção do cotidiano - 1: artes de fazer. Rio de Janeiro: Vozes. (Edição original: 1990). (1995). A cultura no plural. Campinas, SP: Papirus.

ECO, U. (1994). Seis passeios pelo bosque da ficção. São Paulo: Companhia das Letras.

GERALDI, J.W. (1991). Portos de passagem. São Paulo: Martins Fontes.

ISER, W. (1996). O fictício e o imaginário: perspectivas de uma antropologia literária. Rio de Janeiro, EdUERJ. (Edição original: 1991). 
KOCH, I.G.V. (1989). A coesão textual. São Paulo: Contexto.

(1997). O texto e a construção dos sentidos. São Paulo: Contexto.

(mimeo).

(1999). Referenciação: construção discursiva. Campinas, SP: Universidade Estadual de Campinas.

KOCH, I.G.V. \& MARCUSCHI, L.A. (1998). Processos de referenciação na produção escrita. D.E.L.T.A. V. 14. $\mathrm{N}^{\circ}$. Especial, $169-190$.

MAINGUENEAU, D. (1989). Novas tendências em análise do discurso. Campinas, SP: Pontes, Campinas, SP: Editora da UNICAMP. (1995). O contexto da obra literária. São Paulo: Martins Fontes.

. $\left(1996^{\mathrm{a}}\right)$. Elementos de lingüística para o texto literário. São Paulo: Martins Fontes. (1996b). Pragmática para o discurso literário. São Paulo: Martins Fontes.

MARCUSCHI, L.A. (2000). Gêneros textuais: o que são e como se constituem. Recife: Universidade Federal de Pernambuco. (mimeo).

RICOEUR, P. (1995). Tempo e Narrativa. Tomo II. Campinas, SP: Papirus. (Edição original: 1984).

SIMÕES, M.P.S.G. \& GOLDER, C. (1995). (orgs.) Abaetetuba conta. Belém: Cejup, Universidade Federal do Pará. - (Série Pará conta; 3).

. (1995). Belém conta. Belém: Cejup, Universidade Federal do Pará. - (Série Pará conta; 2).

. (1995). Santarém conta. Belém: Cejup, Universidade Federal do Pará. - (Série Pará conta; 1).

WARNER, M. (1999). Da fera à Loira: sobre contos de fadas e seus narradores. São Paulo: Companhia das Letras. 